\title{
Improving Students' Motivation and English Language Skills via NEO Learning Management System
}

\author{
Liann Camille Perez ${ }^{*}$, Anita Triastuti \\ Department of English Language Education, Universitas Negeri Yogyakarta, Yogyakarta, Indonesia \\ "Corresponding author. Email: lianncamilledavalosperez@gmail.com
}

\begin{abstract}
This paper aims to answer the questions of whether NEO learning management system passes the international quality standards for management systems through comparing it with Advanced Distributed Learning (ADL) Standards. Moreover, whether if it is capable of enhancing students' motivation and English language skills. It is characterized as a qualitative research with the use of both descriptive analysis and literature review methodologies. Based on the analyzed data and reviewed literature, it is found out that the features of NEO LMS passed the ADL standards but missed several features. Furthermore, it is capable of enhancing students' motivation and English language skills.
\end{abstract}

Keywords: advanced distributed learning standard, english language skills, educational technology, motivation, neo learning management system.

\section{INTRODUCTION}

Through the globalization of education, learning English language widens connections and creates more meaningful experiences for the students. The English language functions as a global language that facilitates communication among people of different lingua-cultures [1]. Furthermore, it is also found out that English will remain as the universal language for at least the next 15-20 years. Thus, it is significant to improve its learning in order to reach, communicate, and understand people effectively [2].

Though English language's importance is clear and visible, students still have low motivation in acquiring English for different reasons e.g., incompatible activities from real- life situations, different English skills levels, unconducive classroom environment, and conventional way of teaching [3], [4]. As students have less motivation, this will obviously affect their English language skills. Thus, to solve these problems, educators must know the fact that the development of the English language education content equates to the change in its pedagogy or art of teaching. The delivery of the content varies from one era to another, and now mainly aims to modernity [5]. The new discoveries in technology upgrade the traditional way of English teaching. Educators always try to adapt, modify, or even create new approaches to deliver the content in the best way possible [6] Thus, the use of learning management systems like NEO LMS is receiving much attention.

NEO LMS is an online system offered by Cypher Learning Company and used to manage educational activities like creating and delivering educational content, assessing students and analyzing their results, tracking student progress, collaborating on projects, and making learning more interactive and engaging. This system is used around the globe whether it is a simple public kindergarten to famous big universities. In addition, it supports around 40 languages which results in a smooth flow of communication among 
users. It supports various features that teachers may like graphical dashboards, widgets, avatars and profile pictures, pointing systems, gamification, various types of examinations, analytics of students' quiz results, leaderboards, etc. [7]. These features ensure convenient learning and easy access on materials. Positive responses were also gathered from both students and teachers who experienced using NEO LMS like increased class participation and engagement [8], [9] and 50\% improvement from "unsatisfactory" student performances [6].

It is evident that technology places a vital role in acquiring knowledge in this modern era. However, the application of technological advances like NEO learning management system to support English language teaching and learning is not yet explored. This situation might be the future in which again will change the education perspective. Thus, this paper aims to analyze NEO LMS features and find out whether its use enhances the students' motivation and English language skills.

\section{METHODS}

\subsection{Research Design}

This paper is characterized as a qualitative research with the use of both descriptive analysis and literature review methodologies. The NEO learning management system application itself was subjected to descriptive analysis as it was compared to the Advanced Distributed Learning Initiative (ADL standard. The researcher scrutinized the underlying features of the application and whether it surpasses the mentioned international standard.

\subsection{Data Collection Technique}

To collect the necessary data, the researcher adapted the standard checklist cited in the book "Choosing a Learning Management System" by Peter Berking and Shane Gallagher. This book clearly enumerated and explained the important features learning management systems must incorporate in their LMS's applications. The LMS standards were divided into two categories named: A. Standard Features and B. Emerging Trends [10]. Moreover, the literature review methodology was used in collecting the evidence that using learning management system could improve students' motivation and English language skills. The researcher reviewed previous and related studies regarding NEO LMS's application.

\subsection{Research Authenticity}

It is significant to show the paper's authenticity as it is focusing on qualitative data collected. It is significant to present objectivity and unbiased judgment in the paper. In order to fulfill that, the researcher explained the term "trustworthiness". It refers to the degree of confidence in data, interpretation, and methods used to ensure the quality of a study [11]. To establish trustworthiness, these four (4) aspects must be met: credibility, transferability, confirmability, and dependability.

Credibility refers to the researcher's degree of confidence in the collected data. To ensure this aspect in this research, the application's thorough analysis was compared to the existing Advanced Distributed Learning Initiative (ADL) standards for learning management systems; (2) Transferability on the other hand discusses whether the qualitative findings could be applicable in other contexts like similar situations, population, or phenomena. To pass this aspect, the researcher provided an accurate description on how this research is indeed transferable as NEO LMS could be used around the globe by any school or university for it is a technological advancement that could help them in enhancing teaching and learning process; (3) Confirmability is the research study's findings degree of neutrality. The researcher must not be biased or subjective regarding the collected data, and (4) dependability focuses on the extent whether the study could be repeated by other researchers and that the findings would be consistent. This research achieved the two latter aspects as this research used international standards as the basis of NEO LMS analysis and its possible effectiveness.

\section{FINDINGS AND DISCUSSION}

The table below presents the comparison of NEO learning management system to the Advanced Distributed Learning Initiative Standards. The table was adapted and respectfully modified by the author from the book "Choosing a Learning Management System" by Peter Berking and Shane Gallagher. The writer ticked $(\checkmark)$ the available features found.

Table 1. NEO LMS Feature Compared to Advanced Distributed Learning Initiative (ADL) Standards: A. Standard Features.

Learning Management System Features Rating Matrix

\begin{tabular}{|c|c|}
\hline Feature Name & $\begin{array}{l}\text { NEO } \\
\text { LMS }\end{array}$ \\
\hline A. Standard Features & \\
\hline 1. SCORM Supported & $\checkmark$ \\
\hline 2. Internal Assessment Authoring & $\checkmark$ \\
\hline
\end{tabular}




\begin{tabular}{|c|c|}
\hline 3. Internationalization & $\checkmark$ \\
\hline $\begin{array}{l}\text { 4. Instantiation for individual business } \\
\text { units }\end{array}$ & $\checkmark$ \\
\hline 5. LMS sharing & $\checkmark$ \\
\hline 6. The path of least resistance & $\checkmark$ \\
\hline $\begin{array}{l}\text { 7. Registration and enrollment functions } \\
\text { and workflow }\end{array}$ & $\checkmark$ \\
\hline 8. $\begin{array}{l}\text { Notifications, messages, and } \\
\text { annotations }\end{array}$ & $\checkmark$ \\
\hline 9. $\quad$ Batch administration workflow & $\checkmark$ \\
\hline 10. Prerequisite handling & $\mathrm{X}$ \\
\hline 11. Content importing and configuration & $\checkmark$ \\
\hline 12. System access and security & $\checkmark$ \\
\hline 13. Permissions and roles & $\checkmark$ \\
\hline 14. System performance & $\checkmark$ \\
\hline 15. Course catalog database & $\checkmark$ \\
\hline 16. Interface customization & $\checkmark$ \\
\hline 17. Standards and language support & $\checkmark$ \\
\hline $\begin{array}{l}\text { 18. Training infrastructure and } \\
\text { performance analysis }\end{array}$ & $\checkmark$ \\
\hline 19. Learning object management & $\checkmark$ \\
\hline 20. Delivery architecture & $\checkmark$ \\
\hline 21. Cost & $\checkmark$ \\
\hline 22. Assessment authoring and delivery & $\checkmark$ \\
\hline $\begin{array}{l}\text { 23. Mentoring, coaching, and other } \\
\text { developmental scenarios }\end{array}$ & $\checkmark$ \\
\hline $\begin{array}{l}\text { 24. Competency } \\
\text { management and } \\
\text { development/learn } \\
\text { ing plans } \\
\end{array}$ & $\checkmark$ \\
\hline 25. Learner tracking & $\checkmark$ \\
\hline 26. Certificates, forms, polls, and surveys & $\checkmark$ \\
\hline $\begin{array}{l}\text { 27. Interfaces with external systems and } \\
\text { applications }\end{array}$ & $\checkmark$ \\
\hline 28. Metadata support & $\checkmark$ \\
\hline 29. User profiles & $\checkmark$ \\
\hline 30. Resource management & $\checkmark$ \\
\hline 31. Analytics and reports & $\checkmark$ \\
\hline 32. Ease of use for administrators & $\checkmark$ \\
\hline 33. Ease of use for learners & $\checkmark$ \\
\hline 34. Transcripts and other documentation & $\checkmark$ \\
\hline 35. Scalability & $\checkmark$ \\
\hline 36. Vendor characteristics & $\checkmark$ \\
\hline
\end{tabular}

\begin{tabular}{|c|c|}
\hline 37. $\begin{array}{l}\text { User training, technical support, and } \\
\text { documentation }\end{array}$ & $\checkmark$ \\
\hline 38. Media and content support & $\checkmark$ \\
\hline
\end{tabular}

From the comparison done to the standard features of NEO learning management system standards, it is found that all features are available except for Prerequisite Handling. This refers to the action that administrators will set prerequisites for the learners to evaluate their knowledge and skills. From the results, they will be decided as to whether allow the students to enroll in the specific course. In addition, this feature can configure and deliver pre-assessments to test-out learners if they demonstrate the standard mastery the course requires [10].

Table 2. NEO LMS Feature Compared to Advanced Distributed Learning Initiative (ADL) Standards: B. Emerging Trends in LMSs.

\section{Learning Management System Features Rating}

Matrix

\begin{tabular}{|l|l|}
\hline Feature Name & NEO \\
& LMS \\
\hline
\end{tabular}

\section{B. Emerging Trends in LMSs}

\begin{tabular}{|c|c|}
\hline 1. Experience API (xAPI) adoption & $\checkmark$ \\
\hline $\begin{array}{l}\text { 2. Support and optimization for } \\
\text { virtual immersive environments } \\
\text { (VIEs) }\end{array}$ & $\mathrm{X}$ \\
\hline $\begin{array}{l}\text { 3. Support and } \\
\text { optimization for } \\
\text { informal/social/ } \\
\text { collaborative } \\
\text { learning }\end{array}$ & $\checkmark$ \\
\hline $\begin{array}{l}\text { 4. Massive Open Online Course } \\
\text { (MOOC) support }\end{array}$ & $\mathrm{X}$ \\
\hline 5. Open architectures & $\checkmark$ \\
\hline 6. Adding authoring capabilities & $\checkmark$ \\
\hline 7. Extended enterprise learning & $\checkmark$ \\
\hline $\begin{array}{l}\text { 8. Adding knowledge management } \\
\text { architecture and capabilities }\end{array}$ & $\checkmark$ \\
\hline 9. Support for team-based learning & $\checkmark$ \\
\hline 10. "Gadget"- based interface & $\checkmark$ \\
\hline 11. Adding competency analysis tools & $\checkmark$ \\
\hline 12. Multimedia LMS (MLMS) & $\checkmark$ \\
\hline 13. Learning Experience Manager & $\checkmark$ \\
\hline 14. Video conferencing integration & $\checkmark$ \\
\hline 15. Search-based learning & $\checkmark$ \\
\hline
\end{tabular}




\begin{tabular}{|c|c|}
\hline 16. Content delivery networks (CDNs) & $\sqrt{ }$ \\
\hline 17. Integration with digital libraries & 1 \\
\hline 18. Gamification of learning & $\checkmark$ \\
\hline 19. Adaptive learning systems & ( \\
\hline 20. . Content brokering systems & 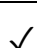 \\
\hline 21. Affective computing & $\mathrm{X}$ \\
\hline $\begin{array}{l}\text { 22. Support for performance support } \\
\text { tools }\end{array}$ & $\checkmark$ \\
\hline 23. Personal Data Lockers (PDLs) & 1 \\
\hline 24. Web-based client systems & 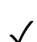 \\
\hline 25. The Flipped Classroom & d \\
\hline 26. Microlearning & 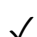 \\
\hline 27. Data analytics & 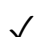 \\
\hline 28. Adaptive learning systems & t \\
\hline 29. Content brokering systems & $\checkmark$ \\
\hline
\end{tabular}

From the emerging trends of learning management systems, NEO LMS has not yet integrated Support and optimization for virtual immersive environments (VIEs) which means the learning management system could provide serious games, first-person simulation, and virtual worlds. Through this feature, the learner can then $\log$ in to their LMS and take eLearning courses while in the VIE platform. Upon analysis, the author only found out that NEO LMS only supports gamification but not the use of virtual worlds or firstperson simulation.

Moreover, the "massive open online courses" (MOOCs) are also not found in the features of NEO LMS. This feature refers to the emerging trend in social media-based courses in which both participants and course materials are distributed across the internet. In addition, the learning principles used in this feature are informal and rely heavily on social media. The learners only participate due to curiosity, level of time, interest, and it has no cost at all. The sponsors of the courses could be the different universities across the world.

Another feature that NEO learning management system is lacking refers to Affective Computing. This is an emerging movement towards adaptive learning in which allows the system to respond dynamically to the user's affective domain of students. This will inform the system of the student's feelings such as when they are confused, anxious, bored, etc. The availability of this feature could enhance the teacher's understanding of the learner's feelings through a constant reading of their posture, tone of voice, and facial expressions.

All in all, the NEO learning management system incorporated almost all of the Advanced Distributed Learning Standards except from the above-mentioned features which means that it could enhance students' motivation and contribute to the success of the student's English language learning in the modern era.

\subsection{NEO Learning Management System in Enhancing Students' Motivation and English Language Skills}

After checking and understanding the underlying features in the NEO learning management system (LMS) application, the next purpose of this research must be answered - whether the application is capable on enhancing students' motivation and English language skills. Previous literature states as follows:

Technological advances like learning management systems is an important tool in today's education as it gives convenience to its end-users [12], [13]. The accessibility of the learning materials in the program helps the students to learn at any time and any place. The program could be downloaded in every technological device like laptops, tablets, mobile phones, etc. thus, learning is possible. As it supports distance learning with freer learning processes, students find higher motivation and interest in learning. In addition, it is found out that student's enthusiasm to learn has increased substantially over the past year especially on the additional resources or their substandard progress in the course increasing from $40 \%$ to $57 \%$, while on guidance course recommendations has increased from $32 \%$ to $62 \%$ [14]. This infers that students' are becoming motivated to learn as they are excited to know the new features of the learning managements systems. Moreover, students are becoming more independent learners as LMSs guide them on what courses are available that suit the learners' needs and interests.

Aside from students' perspectives, $74 \%$ of the teachers using LMS that it is a very useful tool to enhance teaching, while $47 \%$ acquainted it as part of their daily teaching and learning process routine. The numerical presented ensures the positive impact of LMSs in both students' and teachers' role in the learning process. This motivates the students to be better in their classes and guarantees better routine in the teachers' lesson preparations.

Another research was conducted by Chaiprasurt , C., et al. [15]. They learned from the students' data that learning management system's tools are effective 
in improving learners' motivation. Moreover, this believes that it specifically enhances their attention to the lessons and being more engaged to participate in the class.

As progress of students' engagement and motivation in class is positively influenced by the learning management systems, English language skills are also being taken into account. It is it is revealed that an LMS called Blackboard learning - a type of LMS was proven effective in improving the students' writing skills of the experimental group [16]. It is also revealed that there is a positive attitude towards the use of Blackboard learning as a tool for university students. Aside from students' writing skills, learning management systems are also proven capable of enhancing speaking, listening, reading, and vocabulary skills with the use of "TES Teach LMS" [17].

The above-mentioned reports ensure the positive effects of learning management systems in enhancing English language skills.

\section{CONCLUSIONS}

Students need to be more acquainted with the world's lingua franca - English as the globalization of education is emerging swiftly. They should know its importance in building broader communication and connection around the globe. However, students are still unmotivated to learn English which also affects their skills in using the said language. But then, teachers and the education community must not neglect the available advanced technology that could be applied to solve these problems - the usage of learning management systems.

In this paper, the author aimed to analyze whether the NEO learning management system incorporated the Advanced Distributed Learning Standards - which is a set of international standards for management systems. Based on the results gathered, it could be concluded that NEO learning management system creators indeed used the mentioned standards for their own LMS. However, they must also make necessary upgrades on the Prerequisite Handling, Support, and optimization for virtual immersive environments (VIEs), Massive Open Online Course (MOOC) support, and Affective Computing features which are found out not yet available in the system.

In accordance to the LMS's impact on students motivation and English language skills, the reviewed studies provided numerical evidences of its positive effect on both aspects mentioned. Through the use of LMS, students feel more independent and responsible on their own learning and they could enhance their English language skills.

\section{AUTHOR'S SUGGESTION FOR FURTHER RESEARCH}

For future researchers who are interested in this topic, the author suggested incorporating quantitative data analysis to gather a stronger basis of the students' enhanced motivation and English language skills. In addition, other learning management systems could also be added to the analysis to broaden the best choices of the education community when it comes to the use of learning management systems.

\section{RESEARCH LIMITATIONS}

The scope of this paper is only limited to answering the question as to whether the NEO learning management system features to incorporated the international quality standards of the LMSs and if it is capable to motivate the students to learn the English language and improve their skills. The author admits that without supporting quantitative data, the result of this research could be questionable; however, the trustworthiness of the paper was clearly explained in the methodology section.

\section{ACKNOWLEDGMENTS}

The researchers would like to extend her appreciation to her corresponding author and supervisor, Mrs. Anita Triastuti, S. Pd., M. A., Ph. D. for her great advices and guidance during the writing process of this paper. Moreover, deep gratitude is also given towards Almighty God, researcher's family and friends for their support and encouragement.

\section{REFERENCES}

[1] F. Fang, English as a lingua franca: implications for pedagogy and assessment, in TEFLIN Journals, 2017

[2] "Scenario two: english displaces other languages", in Pew Research Center, Internet and Technology, 2006

[3] A. Putri, Low motivation in learning speaking, in Journal Anglo-Saxon Vol.7 No.1., 2016 DOI: https://www.journal.unrika.ac.id/index.php/jurnal anglo- saxon/article/viewFile/491/360

[4] N. Zuniarti, U. Salam, Z. Arifin, Students' motivation in learning English, in Media Publication, 2016

[5] L. Archambault, K. Wetzel, T. S. Foulger, M. K. Williams, Journal of digital learning in teacher 
education, in Professional development 2.02974 (April), 2153-2974, 2016 DOI: https://doi.org/10.1080/21532974.2010.1078461

[6] G. Kakasevski, M. Mihajlov, S. Arsenovski, S. Chungurski, Evaluating usability in learning management system moodle, in ITI 2008 - 30th International Conference on Information Technology Interfaces, 613-618, 2008

[7] Z. Liu, N. Lomovtseva, E. Korobeynikova, Online learning platforms: reconstructing modern higher education, in IJET International Journal of Emerging Technologyin Learning, 2020 DOI: https://online-journals.org/index.php/ijet/article/view/14645.

[8] S. Tumskiy, K. Tkachenok, The impact of mobile learning on teaching English, in SSRN: 2019 DOI: https://ssrn.com/abstract=3502094,

[9] Buenaventura-Vera, G. The impact of leader selfefficacy on the characteristics of work teams, in Intangible Capital, vol. 13, núm. 4, pp. 824-849 Universitat Politècnica de Catalunya Terrassa, España, $2017 \quad$ DOI; http://www.redalyc.org/articulo.oa?id=549533580 07

[10] P. Berking, S. Gallagher, Choosing a learning management system, in Serco Services, Inc. under OPM Contract OPM0207008 Project Code: 02 EA3TTAN MP Vol. 3, 2016.

[11] D. F. Polit, C. T. Beck, Essentials of nursing research: appraising evidence for nursing practice, in Philadelphia, PA: Wolters, Kluwer/Lippincott/Williams \& Wilkins Health, 2014

[12] L. Chaw, C. Tang, What makes learning management systems effective for learning?, in Journal of Educational Technology Systems, 2018

[13] R. Kraleva, V. Kralev, M. Sabani, An analysis of some learning management systems, in International Journal on Advanced Science, Engineering and Information Technology (IJASEIT), 2019

[14] E. Dahlstrom, D. C. Brooks, J. Bichsel, The current ecosystem of learning management systems in higher education: student, faculty, and it perspectives, in Research Report. Louisville,
CO:

ECAR,

2014

(http://www.educause.edu/ecar.)

[15] C. Chaiprasurt, V. Esicaiku, Enhancing Motivation in Online Courses with Mobile Communication Tool Support: A Comparative Study, in International Review of Research in Open and Distance Learning 14(3):377-401, 2013 DOI: 10.19173/irrodl.v14i3.1416

[16] M. Ta'amneh, The effect of blackboard learning on the development of english writing skills among university students, in Journal of Education and Practice,11(19), 83-91, 2020 DOI: 10.7176/JEP/11-19-12

[17] Z, Zainuddin, H. D. Hermawan, F. Nuraini, S. M. Prayitno, Students' learning experiences with $1 \mathrm{~ms}$ tes teach in flipped-class instruction, in ELINVO (Electronics, Informatics, and Vocational Education), 2019 DOI: 10.21831/elinvo.v4i1.24405 